\title{
Use of Twitter to build mental health literacy among medical students and primary care physicians
}

\author{
Chachar, A.S. ${ }^{1}$, Younus, $S^{2}{ }^{2} \&$ Mian, A.I. ${ }^{3}$
}

\begin{abstract}
There is a significant dearth of physicians trained in mental health in Pakistan. Four hundred qualified psychiatrists are making it an alarming ratio of one psychiatrist to half a million people. Due to the lack of basic knowledge, psychiatric care delivered to patients by general practitioners is suboptimal at best. To address this gap, we designed a 36-hour course in principles of mental health aimed at general physicians. The course spanned over two months with weekly sessions. Initially, the methodology was designed for around 50 participants; however, 575 applicants registered in the first three days. Also, contrary to expectations, the majority of these were medical students from other universities. With a few weeks to go, the team reassessed methodology with a new focus on large. We decided to use Twitter to inform maximum engagement both in the classroom and beyond. The aim was to address the individual concerns of students with different levels and needs, to actively engage and build studentteacher relation, to respond to as many individual comments/communications as possible, to encourage in-participant discussion and to ensure instant communication and content sharing. More than 1200 people showed interest on the Facebook event page. 575 learners attended the certificate course. Majority of the participants were students with about $1 \%$ being PCPs. There were 15 multiple choice questions; 2 from each module. The minimal improvement for correct answers on pre-post tests was $9.1 \%$ and the maximum was $36.5 \%$. The first four weeks were the most active for all aspects of the curriculum; interest dwindled in the last few weeks when twitter use was limited more for mandatory functions. The older participants in the audience were not comfortable using the technology platform initially, but later warmed up to its usage. Engagement of guest speakers on Twitter was minimal. Overall our experience shows that a twitter platform was helpful in creating engagement of participants in a 2 month weekly course of a large $>500$ student setting. Further research is needed to ascertain if a combination of engagement methodologies would be more successful in sustaining interest over a long course.
\end{abstract}

Key words: Twitter, capacity building, curriculum development

\section{Introduction}

The shortage of mental health professionals worldwide, relative to the burden of disease is well-documented.

${ }^{1}$ Child and Adolescent Psychiatry fellow, Department of Psychiatry, Aga Khan University, Pakistan

${ }^{2}$ CAP Fellowship (AKU), General, Child and Adolescent Psychiatrist

${ }^{3}$ Diplomate ABPN, General, Child and Adolescent Psychiatrist, Chair and Associate Professor, Department of Psychiatry, Aga Khan University Hospital

Corresponding Author:

Dr. Aisha S. Chachar,

Child and Adolescent Psychiatry fellow, Department of Psychiatry, Aga Khan University, Karachi, Sindh Pakistan

Email: aishachachar87@gmail.com

DOI: http://doi.org/10.4038/seajme.v13i1.56
In most countries, the first point of contact for these disorders are the primary care physicians (PCPs), or in some instances, faith healers. This highlights the importance of mental health $(\mathrm{MH})$ literacy for primary care physicians in this domain. Learning of basic knowledge of $\mathrm{MH}$ care at the undergraduate level also becomes integral to ensure that all graduating physicians can screen, treat mild to moderate psychiatric disorders and refer when needed.

Capacity building programs (CBP) can optimize the competency of primary care physicians in the domain of MH (Patel et al., 2011). CBD may take several forms, ranging from workshops, seminars and certificate courses. Many countries have used certificate courses/training programs as a tool to build capacity in mental 
health services for primary care providers. Recent examples include projects from Uganda and India where capacity building initiatives were devised for the non-specialist health workers and showed significant effectiveness. In resource-poor countries, this methodology can act as a first step towards sensitizing primary care providers and students towards mental health. In 2009, the WHO launched a mental health gap action program (mhGap) to bridge this gap by providing evidence-based services. Short courses have an essential role to play in enhancing the capacity of PCPs through improving their knowledge, attitude and clinical practice (Clarke et al., 2006).

Similarly, nursing staff shortage, the need for indepth education and training in specific knowledge content areas led to the approach of career-long learning certificate programs (Craven \& DuHamel, 2003). Due to the challenge of paucity of $\mathrm{MH}$ professionals and even fewer with academic interest, programs with short duration and use of innovative and creative teaching methodologies can have a more significant impact.

Pakistan has 350-400 qualified psychiatrists catering to a population of approximately 207 million. This creates an alarming ratio of one psychiatrist to about a million people (Khan, 2016). With 110 medical schools, the country graduates around 15-20,000 students every year. The $\mathrm{MH}$ training of these medical students as well as practicing PCPs, however, is minimal. Majority of medical schools do not have a mandatory undergraduate psychiatry curriculum and therefore do not evaluate students for $\mathrm{MH}$ competencies. These students are unlikely to choose psychiatry as a specialty due to lack of exposure, which further increases the treatment gap. In terms of active clinical practice, there are around 110,000 PCPs in the country (Sabzwari, 2015). Patients with $\mathrm{MH}$ disorders are likely to use them as the first line of contact due to the ease of access and lack of awareness of disorders. They are also likely to bring up psychiatric symptoms to other specialists that they may be seeing. Both the graduating physicians who may go on to practice other specialties, as well as PCPs, are likely to miss psychiatric symptoms, misdiagnose or practice poly-pharmacy due to lack of adequate training. PCPs lack knowledge of internationally recognized diagnostic categories for mental disorders and choice of drugs for these disorders (Naqvi, 2012). As one of the steps towards bridging this gap, an elementary $\mathrm{MH}$ course was designed for medical students and general physicians (Toews, 2004). This course aimed to increase $\mathrm{MH}$ literacy amongst medical students and PCPs.

\section{Methods}

The curriculum was developed through multiple focus group meetings of experts in the field of $\mathrm{MH}$. The objectives of the curriculum included identification of the common psychiatric disorders that present to general medical settings, management of mild-moderate psychiatric conditions, recognition the need to refer to specialists, differentiation between the myths and the facts associated with $\mathrm{MH}$ symptomology. The team contextualized the curriculum content to the community health needs of Pakistan and used illustrative examples with local and cultural applicability. For ease of curriculum design and teaching and learning $(T / L)$ methodology curriculum was divided into five modules that were taught in 8 sessions (Table 1).

\section{Table 1: Over all objectives of the course and modules}

\begin{tabular}{|c|c|}
\hline Modules & Objectives \\
\hline $\begin{array}{l}\text { 1. Foundation module which addressed } \\
\text { communication skills and ethical practices in } \mathrm{MH} \\
\text { 2. Mood and Anxiety disorders } \\
\text { 3. Psychotic disorders and substance abuse } \\
\text { disorders } \\
\text { 4. Child and adolescent } \mathrm{MH} \text { disorders } \\
\text { 5. Consultation-liaison psychiatry }\end{array}$ & $\begin{array}{l}\text { By the end of this course students will be able to } \\
\text { - } \quad \text { Identify the common psychiatric disorders that } \\
\text { present to general medical settings } \\
\text { - } \quad \text { Manage mild-moderate psychiatric conditions } \\
\text { - } \quad \text { Recognize the need to refer to specialists } \\
\text { - Differentiate between the myths and the facts } \\
\text { associated with mental health symptomology }\end{array}$ \\
\hline
\end{tabular}

The $T / L$ methods emphasized maximum student engagement using videos, social media and direct poll. For effective interaction as well as dissemination of evaluation and assessment tools, AKU's Department of Continuing Professional Education designated this 
educational activity for a maximum of 17.00 the American Association of Continuing Medical Education (AACME) Category 1 Credit(s). The course was implemented as a weekly 2 -hour session spanning across eight weeks. A total of 15 professionals taught during the course. The presenters were assigned the topics based on their expertise in specialty areas of $\mathrm{MH}$, including psychiatry, psychology, neurology, child \& adolescent psychiatry, family medicine and substance abuse rehabilitation. Each presenter had 20 minutes of time allotment for the presentation followed by 10 minutes of participant interaction. The presenters addressed specific objectives for the session devised during curriculum development. Each teaching session was designed using standardized learning outcomes. It included four presentations with a short break in between. The core team emphasized on a standardized template for all talks.

\section{Use of Twitter}

Given that this was a novel initiative, the team had a minimal idea of participant interest and thus designed the course with 50-70 participants in mind. Almost 1200 people showed interest via the Facebook event page. Out of them, we received 575 registrations. Due to limited capacity, the registrations closed after 72 hours. To address this staggering number of registrations, the team revisited the methodology.

A literature search showed that Twitter had been used effectively in longer courses for large classroom settings (Moraitis \& Zegeye, 2016). It was shown to enhance student-student and student-faculty interactions and engagement during and in between sessions. We used Twitter to address the individual concerns for students with different levels and needs, actively engage and build student-teacher relation, respond to as many individual comments/communications as possible and encourage in-participant discussion, instant communication and content sharing. A course hashtag, \#PCC was assigned.

During the introductory session, students received a brief Twitter training. All participants were asked to set up a twitter account; with the support of our IT department who worked around the potential problem of Wifi accessibility by assigning a separate router for the course participants. Ground rules of netiquettes were communicated.

Considering strict work/study timetables and personal/professional commitments of attendees, the course ran for 2 hours every Wednesday afternoon for eight weeks. This was a paid course with a minimal cost for students. 10 volunteers were recruited for managing the logistics such as maintenance of the Twitter account, data collection of evaluations as well as maintaining considerable classroom discipline during and between sessions. A Facebook event page had been created in the beginning to disseminate information about the course and to gather registrations. This page was closed once the course started and the Twitter account became the primary source for functional communication. The cost of the event was nominal and further subsidized for the medical students. It was Rs. 1500 (12.95 USD) for PCPs and Rs. 500 (4.32 USD) for medical students.

(USD to Pakistan Rupees Forex Exchange Rates - 1.00 USD =116.70 PKR

Updated: April 13 2018)

There were 15 multiple choice questions for pre and post-test. These MCQs focused on the salient teaching points from the extent of the course, usually based on harm prevention and minimal standard guidelines. Learners were asked to complete questionnaires after each session. The evaluation assessed whether objectives were met at the end of the session, simplicity was appropriate for the audience, clarity of audio-visual content, clarity of the 'take-home message,' presenter engagement and enthusiasm and overall rating of the activity. Participants rated these items on 5 points Likert scale ranging from Poor to Excellent. Open-ended questions addressed what they found helpful and areas of improvement.

\section{Results}

More than 1200 people showed interest on the Facebook event page. 575 learners attended the certificate course. Figure 1 shows the number of participants who filled the pre-post tests and assessments. 


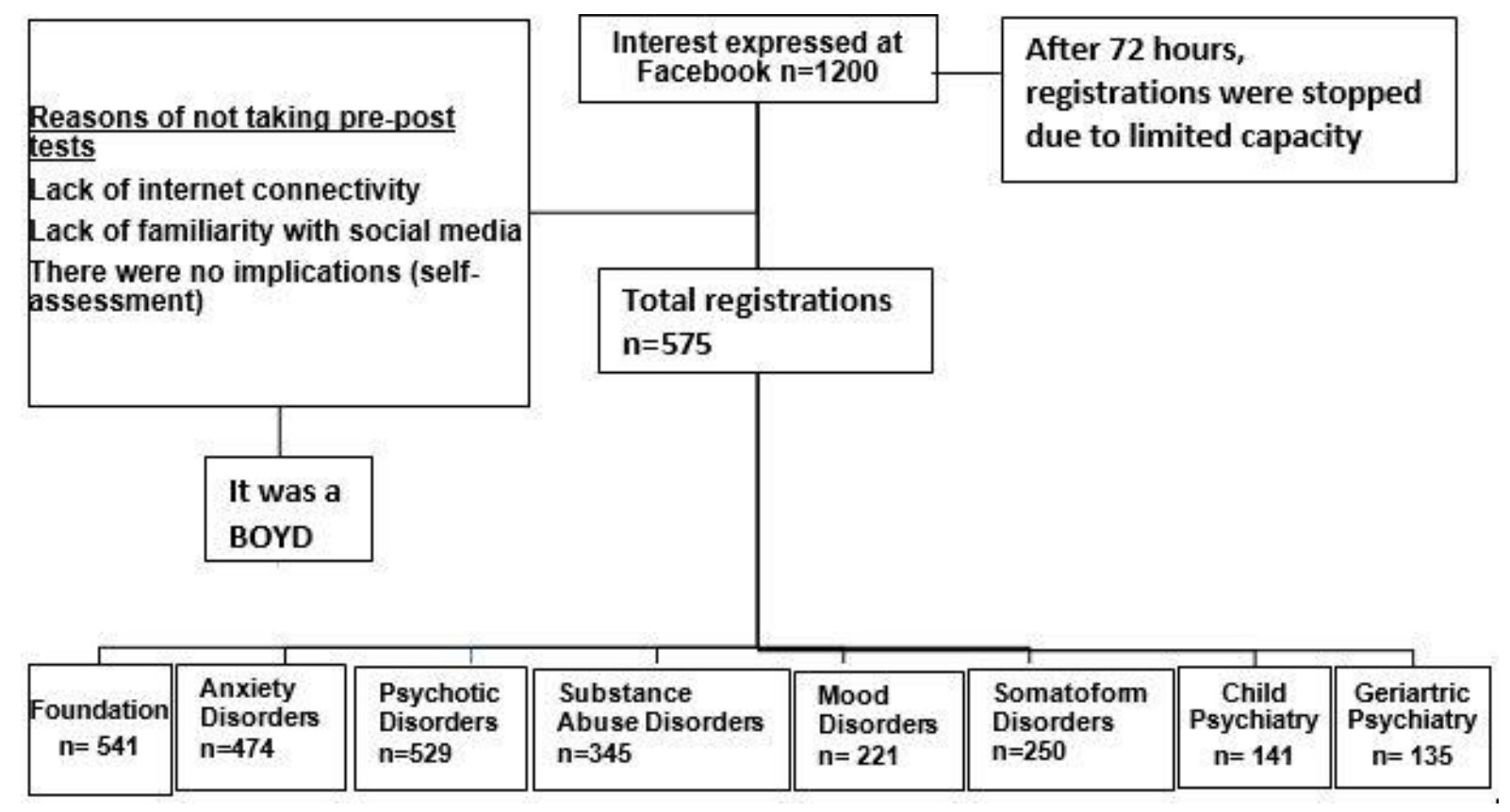

Figure 1: Number of participants who filled the pre-post tests and evaluations

Majority of the participants were students with about $1 \%$ being PCPs; $79.60 \%$ were females. There were 15 multiple choice questions; 2 from each module. Table 2 shows the change in the correct responses after the training. The minimal improvement was found out to be $9.1 \%$ and the maximum was $36.5 \%$. The Twitter account received $14.6 \mathrm{k}$ profile visits and 534 followers during the first four weeks of the course. \#PCC was mentioned in 299 tweets during the eight weeks, of the course (Table 3).

Table 2: Improvement in correct responses of pre-post tests

\begin{tabular}{|c|c|c|c|}
\hline Questions & $\begin{array}{l}\text { Pretest } \\
\text { correct }\end{array}$ & $\begin{array}{c}\text { Posttest } \\
\text { correct }\end{array}$ & Difference \\
\hline $\begin{array}{l}\text { 1. The first line treatment for Mild-Moderate Depressive episode is: } \\
\text { - Antidepressants } \\
\text { - ECT } \\
\text { - Hospital Admission } \\
\text { - Mood stabilizers } \\
\text { - Physical exercise + supportive counseling }\end{array}$ & $79.4 \%$ & $89.0 \%$ & $9.6 \%$ \\
\hline $\begin{array}{l}\text { 2. A } 7 \text { years old girl comes to you with complaint of hyperactivity, } \\
\text { impulsivity and inattention. Your diagnosis is ADHD. The treatment } \\
\text { may include all the following except: } \\
\text { - Behavioral therapy } \\
\text { - Psycho education } \\
\text { - Risperidone } \\
\text { - School based interventions } \\
\text { - Stimulants }\end{array}$ & $30.6 \%$ & $53.7 \%$ & $23.1 \%$ \\
\hline $\begin{array}{l}\text { 3. The black box warning for Selective Serotonin Reuptake Inhibitors } \\
\text { (SSRIs) includes caution about: } \\
\text { - Anaphylactic Reaction } \\
\text { - Hepatic failure } \\
\text { - Pancreatitis } \\
\text { - Renal failure } \\
\text { - Suicidality }\end{array}$ & $48.7 \%$ & $74.1 \%$ & $25 . \%$ \\
\hline
\end{tabular}




\begin{tabular}{|c|c|c|c|}
\hline Questions & $\begin{array}{l}\text { Pretest } \\
\text { correct }\end{array}$ & $\begin{array}{c}\text { Posttest } \\
\text { correct }\end{array}$ & Difference \\
\hline $\begin{array}{l}\text { 4. Most commonly abused prescribed medication is: } \\
\text { - Anti-Depressants } \\
\text { - Antibiotics } \\
\text { - Benzodiazepines } \\
\text { - Mood stabilizers } \\
\text { - Pain medications }\end{array}$ & $23.5 \%$ & $60.0 \%$ & $36.5 \%$ \\
\hline $\begin{array}{l}\text { 5. } 9 \text { year old boy with well-established diagnosis of Intellectual Disability } \\
\text { (previously called Mental Retardation) now presents with severe } \\
\text { behavioral problems. First line management will be: } \\
\text { - Hospitalization } \\
\text { - Low dose atypical antipsychotics } \\
\text { - Neurotonics } \\
\text { - Parent Behavioral management training }\end{array}$ & $61.3 \%$ & $73.3 \%$ & $15 \%$ \\
\hline $\begin{array}{l}\text { 6. Which of the following is a mandatory step for ECT administration? } \\
\text { - Epidural Anesthesia } \\
\text { - General anesthesia without informed consent for best interest of } \\
\text { patient } \\
\text { - Informed consent and General Anesthesia } \\
\text { - Physical restraint } \\
\text { - Spinal Anesthesia }\end{array}$ & $58.0 \%$ & $75.3 \%$ & $17.3 \%$ \\
\hline $\begin{array}{l}\text { 7. Most important aspect in the clinical assessment of a psychiatric patient } \\
\text { is evaluation of: } \\
\text { - Family history of psychiatric illness } \\
\text { - Marital history } \\
\text { - Risk of self-harm and harm to others } \\
\text { - Social history } \\
\text { - Spiritual beliefs }\end{array}$ & $31.0 \%$ & $53.7 \%$ & $22.7 \%$ \\
\hline $\begin{array}{l}\text { 8. In addition to Cognitive Behavior Therapy the following is the medication } \\
\text { of choice for treatment of GAD: } \\
\text { - Antipsychotics } \\
\text { - Benzodiazepines } \\
\text { - Mood stabilizers } \\
\text { - Selective serotonin reuptake inhibitors } \\
\text { - Tricyclic Antidepressants }\end{array}$ & $29.1 \%$ & $58.8 \%$ & $29.7 \%$ \\
\hline $\begin{array}{l}\text { 9. Which of the following medications can cause dependence if prescribed } \\
\text { for more than } 4-6 \text { weeks in anxiety disorders: } \\
\text { - Alprazolam } \\
\text { - Citalopram } \\
\text { - Fluoxetine } \\
\text { - Propranolol } \\
\text { - Sertraline }\end{array}$ & $43.0 \%$ & $58.0 \%$ & $15 \%$ \\
\hline $\begin{array}{l}\text { 10. Baseline evaluation before starting an atypical antipsychotic should be } \\
\text { done for } \\
\text { - Dystonia } \\
\text { - Leucopenia } \\
\text { - Metabolic Syndrome } \\
\text { - Neuroleptic malignant syndrome } \\
\text { - Pancreatitis } \\
\end{array}$ & $31.2 \%$ & $51.0 \%$ & $19.8 \%$ \\
\hline $\begin{array}{l}\text { 11. Depression is most closely co-related with: } \\
\text { - Coronary artery disease } \\
\text { - Cushing's Disease } \\
\text { - Diabetes } \\
\text { - Hypertension } \\
\text { - Hypothyroidism }\end{array}$ & $40.5 \%$ & $63.1 \%$ & $22.6 \%$ \\
\hline $\begin{array}{l}\text { 12. The commonest type of dementia is: } \\
\text { - Alzheimer's dementia } \\
\text { - Frontotemporal dementia } \\
\text { - Lewy-body dementia } \\
\text { - Parkinsonian dementia } \\
\text { - Vascular dementia }\end{array}$ & $70.5 \%$ & $79.6 \%$ & $9.1 \%$ \\
\hline
\end{tabular}




\begin{tabular}{|c|c|c|c|}
\hline Questions & $\begin{array}{l}\text { Pretest } \\
\text { correct }\end{array}$ & $\begin{array}{l}\text { Posttest } \\
\text { correct }\end{array}$ & Difference \\
\hline $\begin{array}{l}\text { 13. The most important risk factor for dementia is } \\
\text { - Age } \\
\text { - Gender } \\
\text { - Head trauma } \\
\text { - High blood pressure } \\
\text { - Illiteracy }\end{array}$ & $72.1 \%$ & $81.2 \%$ & $9.1 \%$ \\
\hline $\begin{array}{l}\text { 14. A } 35 \text { year old male presents to Emergency Room with complaints of } \\
\text { tremor, clouding of consciousness and visual hallucinations. He has a } \\
\text { history of Alcohol Dependence for past } 5 \text { years. On History last drink is } \\
\text { reported to be } 3 \text { days ago. What is the most probable diagnosis: } \\
\text { - Acute Intoxication } \\
\text { - Alcoholic hallucinosis } \\
\text { - Delirium tremens } \\
\text { - Korsakoff syndrome } \\
\text { - Wernicke's encephalopathy }\end{array}$ & $21.0 \%$ & $47.5 \%$ & $26.5 \%$ \\
\hline $\begin{array}{l}\text { 15. The best predictor of violence in a patient is: } \\
\text { - A family history of violence } \\
\text { - A history of dementia } \\
\text { - A history of substance abuse } \\
\text { - A prior history of conduct disorder } \\
\text { - A prior history of violent acts }\end{array}$ & $39.9 \%$ & $58.8 \%$ & $18.9 \%$ \\
\hline
\end{tabular}

Table 3: Twitter analytics

\begin{tabular}{lccc}
\hline & $\mathbf{1}^{\text {st }}$ four weeks & Last four weeks & Month after the course ended \\
\hline Tweets & 107 & 40 & 21 \\
Profile visits & 14,600 & 3,641 & 2,995 \\
Mentions & 235 & 53 & 46 \\
New followers & 534 & 107 & 11 \\
\hline
\end{tabular}

$42.5 \%$ rated the course excellent on the overall rating of the activity; $29.3 \%$ rated it outstanding. Qualitative feedback praised the interaction and student engagement despite the large classroom. Additionally, they specifically praised the facilitator's enthusiasm, the organization and content of the event and social media use (Kent-Smith, 2002). Comments included "wonderful experience," "amazinglyinteractive," "informative," "Very interesting and informative. Developed our interest in the psychiatry." For suggested improvements, they recommended better time management and less student enrolment to ensure a greater class engagement.

\section{Discussion}

This was the first Psychiatry Certificate Course that catered a vast range of participants who attended the pilot course. It is essential to look at it in the context of minimal teaching of Psychiatry countrywide. Mental health training in Pakistan is at the very early stages. Majority of schools do not have a mandatory undergraduate psychiatry curriculum and therefore do not evaluate students for mental health competencies. This dearth is primarily due to the dearth of academic psychiatry faculty in most medical colleges who find themselves stretched thin between patient care, postgraduate training of residents and doing research.

One of the reasons why we received this sudden influx of expression of interests, especially by undergraduate students, can be attributed to curiosity and seeking knowledge of a neglected subject, even though Psychiatry is a part of major international and national postgraduate professional exams. Secondly, the experts-role models of the specialty routinely inspire the younger and more impressionable students making inspiration another reason why medical students tended to be more (Bhattacharya, 2014). Lecture-format teaching 
and unsolicited printed material (including clinical guidelines) do not make most Continuous Medical Education (CME) successful (Harrison \& Hogg, 2003). Our initial plan was to provide printed handouts. After revisiting our active teaching methodology, we decided to make the resources available online. However, this was not disclosed in any marketing flyers. In Pakistan, research has shown that $74.7 \%$ of general physicians (GPs) believe that they lacked information in this specialized area. When asked if they had attended any courses, workshops or CMEs about mental disorders during the last three years $69.2 \%$ reported that they had not, while $30.6 \%$ had had some form of continuing medical education. $48.9 \%$ showed interest in attending such training. Although GPs report that they do not have enough time for the management of mental disorders, they also believe that patients were unable to afford to attend specialist psychiatric services.

The course rating was overall high, and the use of videos, direct poll, interactive discussion and live tweeting was positively received. Suggestions included customization to the needs of the diverse backgrounds of attendees and more in-depth training in treatment modalities. Participants wanted more detailed knowledge about management specifically of more commonly seen disorders.

Longitudinal follow-up could assess whether this course prompted interest in psychiatry, leading to a change in career choices and clinical application (Kent-Smith, 2002) of the knowledge learned. Future events could encourage all participants to complete questionnaires, to monitor attendance demographics and use better statistical analysis methodology. We are hopeful that besides the acquisition of knowledge, the course increased sensitization of students and physicians towards $\mathrm{MH}$ disorders, decreased stigma, and increased their comfort in screening, management and referral patterns for patients.

Live streaming, follow-up blogs, podcasts and a broader e-learning program could expand this model's influence beyond a single event. In order to attract students who are interested in psychiatry, future iterations of this course could include collaborations with a range of student societies and postgraduate associations, bridging gaps between specialties. Social media evolves continuously: this event must adapt to remain attractive, accessible and relevant to new cohorts of medical students and physicians. The use of social media in psychiatric education is still in infancy, although it has the potential to facilitate international and cross-cultural communities of practice (Roy et al., 2016). The growing availability of internet and smartphone technology means that creative e-learning adaptations of traditional teaching methods have the potential to expand the much needed $\mathrm{MH}$ training across the nation and the globe. Promising results and ease of use of social media has provided the confidence to use the methodologies like blended learning and flipped classroom for subsequent courses.

\section{Implications for educators:}

- In countries where there is no standardization of $\mathrm{MH}$ education in medical students, short certificate courses can act as a vital portal of disseminating basic knowledge around the diagnosis and management of $\mathrm{MH}$ disorders.

- Such courses facilitate achievement of the desired objectives in both cognitive and affective domains, utilizing the expertise of professionals in a time and a cost-effective manner

- Use of social media platforms can provide a useful tool for engaging students in large classroom settings specifically for extended courses.

- It is also essential to design content based on specific community health needs of $\mathrm{MH}$.

\section{References}

Bhattacharya, S. (2014) Was attending the conference worth value for money? Indian journal of plastic surgery: official publication of the Association of Plastic Surgeons of India, 47, 1, pp. 1-3

Clarke, D., Smith, G., Peake, J.A., Trauer, T., McCall, L., Blashki, G. \& Piterman, L. (2006) Evaluation of a short course in psychiatry for general practitioners, Australasian Psychiatry, 14,1 , pp. $76-80$

Craven, R.F. \& DuHamel, M.B. (2003) Certificate programs in continuing professional education, The Journal of Continuing Education in Nursing, 34, 1, pp. 14-18

Harrison, C., \& Hogg, W. (2003). Why do doctors attend traditional CME events if they do not change what they do in their surgeries? Evaluation of doctors' reasons for attending a traditional CME program, Medical education, 37, 10, pp. $884-888$ 
Kent-Smith, L. (2002) The impact of short courses on daily practice, Clinical Nutrition, 21, pp. 160-162

Khan, M.M. (2016) Economic burden of mental illnesses in Pakistan, Journal of Mental Health Policy and Economics, 19, 3, p. 155

Moraitis, I. \& Zegeye, M.I. (2016) Expanding the use of Twitter for medical education, Medical Education Online, 21, 1

Naqvi, H.A., Sabzwari, S., Hussain, S., Islam, M., \& Zaman, M. (2012) General practitioners' awareness and management of common psychiatric disorders: a community-based survey from Karachi, Pakistan
Patel, V., Boyce, N., Collins, P.Y., Saxena, S. \& Horton, R. (2011) A renewed agenda for global mental health, Lancet (London, England), 378, 9801, pp. 1441-1442

Roy, D., Taylor, J., Cheston, C.C., Flickinger, T.E. \& Chisolm, M.S. (2016) Social media: portrait of an emerging tool in medical education, Academic Psychiatry, 40, 1, pp. 136-140

Sabzwari, S.R. (2015) The case for family medicine in Pakistan, JPMA, 65, 6, pp. 660-664.

Toews, J. (2004) How to improve the impact of short courses and workshops, Journal of Continuing Education in the Health Professions: Winter, 24, 1, p. 64 